\title{
Clinical characteristics and therapeutic outcomes of mediastinal neuroblastoma with intraspinal extension: a retrospective study
}

\author{
Jue Tang $^{1 \#}$, Dan Zhang ${ }^{2 \#}$, Ying-Yi Xu ${ }^{3}$, Xin-Ke Xu ${ }^{4}$, Feng-Hua Wang ${ }^{1}$, Jia-Hang Zeng ${ }^{1}$, Jiang-Hua Liang ${ }^{1}$, \\ Wei Liu ${ }^{1}$, Le Li $^{1}$ \\ ${ }^{1}$ Department of Pediatric Surgery, Guangzhou Women and Children's Medical Center, Guangzhou, China; ${ }^{2}$ Reproductive Medicine Center, The \\ First Affiliated Hospital of Sun Yat-Sen University, Guangzhou, China; ${ }^{3}$ Department of Anesthesia, Guangzhou Institute of Pediatrics, Guangzhou \\ Women and Children's Medical Center, Guangzhou, China; ${ }^{4}$ Department of Neurosurgery, Guangzhou Institute of Pediatrics, Guangzhou Women \\ and Children's Medical Center, Guangzhou, China \\ Contributions: (I) Conception and design: J Tang, D Zhang, L Li, W Liu; (II) Administrative support: L Li, W Liu; (III) Provision of study materials \\ or patients: J Tang, YY Xu, XK Xu, FH Wang, JH Zeng, JH Liang, W Liu, L Li; (IV) Collection and assembly of data: J Tang, D Zhang, L Li; \\ (V) Data analysis and interpretation: J Tang, D Zhang, L Li; (VI) Manuscript writing: All authors; (VII) Final approval of manuscript: All authors. \\ \#These authors contributed equally to this work. \\ Correspondence to: Wei Liu; Le Li. Department of Pediatric Surgery, Guangzhou Institute of Pediatrics, Guangzhou Women and Children's Medical \\ Center, Guangzhou Medical University, 9 Jinsui Road, Guangzhou 510623, China. Email: Psurgerytj@163.com; doctorlile@aliyun.com.
}

Background: Mediastinal neuroblastoma (NB) can invade the spinal canal and result in spinal cord compression. Some patients go on to develop severe spinal deformities after decompression of the spinal cord. The optimal therapeutic strategy for mediastinal NB with intraspinal extension is still unclear. Our study is to assess the therapeutic strategies for such patients.

Methods: A total of 77 patients suffered mediastinal tumors with intraspinal extension between March 2015 and Aug 2019 were enrolled in the study. According to the primary therapy, NB were classified into 4 groups: chemotherapy, video-assisted thoracoscopic surgery (VATS)/thoracotomy, neurosurgical decompression, and a combined thoracic-neurosurgical approach. Clinical features, including patient demographics, neurologic recovery and survival rate, were assessed.

Results: Among the 77 patients suffered mediastinal tumors with intraspinal extension, neurological symptoms were present in 44 patients. Neurological deficits improved in $76.5 \%$ of patients who underwent neurosurgical intervention and $50 \%$ of the other patients $(\mathrm{P}=0.094)$. Compression manifestations of $\leq 4$ weeks duration showed an improved outcome compared to a longer compression time, with complete recovery of neurological function in $60 \%$ of patients versus $28.6 \%$ for patients with a longer symptom duration $(\mathrm{P}=0.04)$. NB constituted $49.4 \%$ of the 77 patients. An overall survival rate of $90.0 \% \pm 9.5 \%$ was achieved for patients in the combined thoracic-neurosurgical group, $59.5 \% \pm 15.0 \%$ in the thoracotomy group, $40.0 \% \pm 29.7 \%$ in laminectomy group, and $37.0 \% \pm 20.2 \%$ in the chemotherapy group. Complete regression of the tumor was demonstrated in $80 \%$ of combined group, which was greater than that of patients in the other groups $(\mathrm{P}=0.001)$.

Conclusions: Neurological recovery was correlated with the type of initial treatment and the duration of neurological symptoms. Mediastinal NB with intraspinal extension can be effectively managed with a combined neurosurgical and thoracic surgical approach.

Keywords: Neuroblastoma (NB); spinal cord compression; posterior mediastinal tumor; treatment; outcome

Submitted Aug 26, 2020. Accepted for publication Feb 26, 2021.

doi: $10.21037 /$ tp-20-268

View this article at: http://dx.doi.org/10.21037/tp-20-268 


\section{Introduction}

Posterior mediastinal tumors may result in an epidural mass with or without associated spinal cord compression by infiltrating the intervertebral foramina and invading the spinal canal. Neuroblastoma (NB) is the most common posterior mediastinal tumor, approximately $10-15 \%$ of which are reported to extend into the spinal canal (1-3). Depending on the extent of spinal cord compression, patients may present with sphincter dysfunction, pain, and motor and sensory deficit $(4,5)$. Furthermore, $50 \%$ of these patients develop permanent sequelae, which are more severe in younger children (6-9).

Early decompression of the spinal cord either by neurosurgical intervention or thermotherapy may prevent irreversible neurological changes $(1,10,11)$. Neurosurgical intervention results in immediate spinal decompression but is also associated with postlaminectomy deformity and surgical risk $(1,3,12,13)$. To avoid surgical risk and postoperative complications, chemotherapy was an excellent alternative for NB with intraspinal extension $(11,14)$. However, neurological function had been found to be not improve or aggravated in $30 \%$ of patients received chemotherapy (15-17). Some studies have already reported on spinal cord compression in NB $(3,5)$. However, these studies almost exclusively focused on the neurological function of patients with abdominal NB. At present, a consensus has not been reached regarding the optimal therapeutic strategy for NB with intraspinal extension $(3,18,19)$.

We conduct this study to present the clinical characteristics of patients suffering from mediastinal NB with intraspinal involvement at our single center, and it is expected that our finding will contribute towards the management of patients with this condition. We presented the following article following the STROBE reporting checklist (available at http://dx.doi.org/10.21037/tp-20-268).

\section{Methods}

In the present study, a total of 335 patients who were younger than 16 years old and diagnosed with a mediastinal tumor between March 2015 and Aug 2019 in our center were screened. A total of 77 children who had a posterior mediastinal tumor with intraspinal involvement were included in the study. There were 40 males and 37 females, with a male-female ratio of $1.08: 1$. The patients' ages at diagnosis ranged from 2 months to 13 years, with a median age of $31.7 \pm 32.0$ months.
The study was conducted in accordance with the Declaration of Helsinki (as revised in 2013). This study was approved by the Ethics Committee of Guangzhou Women and Children's Medical center (No. 2017120103-2). Written informed consent was obtained from the parents or guardians of each participant.

The clinical data, including clinical manifestations, time interval from neurological symptoms to diagnosis, pathological types, initial therapeutic regimen, and date of last medical follow-up, were analyzed retrospectively. Computed tomography (CT) was performed in all patients. Magnetic resonance imaging (MRI) was considered when the intraspinal extension was suspected. MRI and surgical reports were reviewed to determine the extent of intraspinal involvement and epidural compression level. The diagnosis was made based on histopathology combined with imaging studies and biochemical profiling. NB was staged according to the International Neuroblastoma Staging System (INSS). According to the initial therapeutic regimen, patients with NB were classified into 4 groups: chemotherapy, videoassisted thoracoscopic surgery (VATS)/thoracotomy, neurosurgical decompression, and combined thoracicneurosurgical approach (Figure 1).

The tumor sites were re-assessed at regular intervals during follow-up. According to a previous study (16), the neurological deficits were classified into mild, moderate, and severe. Patients with paresis alone were considered to have mild neurological deficits, while patients with paraplegia were categorized as severe. Patients were classified as having moderate deficits when they suffered paresis and bladder or bowel dysfunction. Neurological recovery was defined as follows: stage 1 , complete recovery, including fully regained motor power and skills, reflexes; stage 2, partial recovery; stage 3 , stationary, including absent signs of neurological improvement and persistent symptoms of the same intensity; and stage 4. worsening, including newly developed neurological symptoms or worsening of previously present manifestations.

\section{Statistical analysis}

Quantitative data were represented by mean \pm standard deviation. Percentages described qualitative data and the comparison of these data was performed using the Chisquare test. Kaplan-Meier survival analysis was used to assess the median survival probability. All analyses were performed using SPSS 21.0 software (SPSS, Inc., Chicago, IL, USA) and $\mathrm{P}<0.05$ was considered statistically 

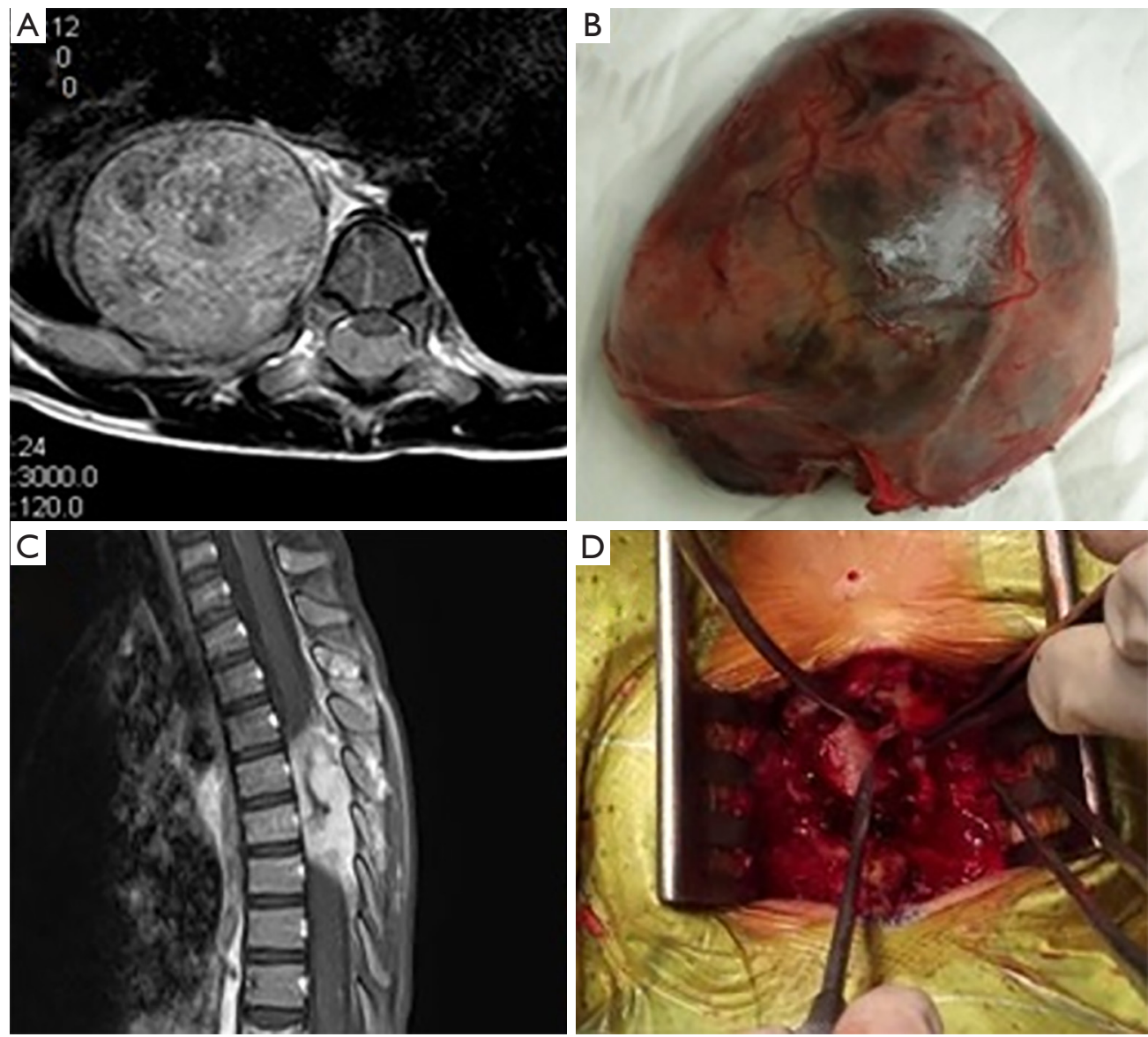

Figure 1 Surgical excision for the dumbbell neuroblastoma. (A) Mediastinal neuroblastoma with in spinal involvement; (B) mediastinal neuroblastoma; (C) spinal cord compression; (D) neurosurgical decompression with laminotomy and tumour excision.

significant.

\section{Results}

\section{Patient characteristics}

There were 77 patients enrolled in the study, including 5 patients who were lose to follow-up. The follow-up period was 1-5 years. The characteristics of these patients are shown in Table 1. Neurogenic tumors constituted $83.1 \%$ of cases, including 38 cases NB, 13 case of ganglioneuroblastoma, 10 case of ganglioneuroma, 1 case each of paraganglioma and pheochromocytoma, and 2 case of the primitive neuroectodermal tumor (PNET) (Table 1). Non-neurological tumors included 5 cases of lymphoma (34.9\%), 4 case of teratoma (3.4\%), 2 cases of rhabdomyosarcoma, and 2 cases of other tumor types. $\mathrm{NB}$ was the most common cause of spinal canal extension. CT or endobronchial ultrasound-guided fine-needle aspiration cytology (FNAC) was performed in 12 patients. Three patients with ganglioneuroblastoma were initially misdiagnosed with ganglioneuroma by FNAC. We also found 2 patients who had posterior mediastinal NB and intraspinal ganglioneuroma with different histological entities.

Twenty-six patients $(33.8 \%)$ were asymptomatic and detected incidentally by radiological evaluation, while 51 patients $(66.2 \%)$ were symptomatic. Neurological symptoms were the most common complaint, including 14 patients with paraparesis, 34 with weakness of the lower limbs or pain, and 16 with incontinence of urine or stool. The presenting symptom was polypnea in 8 patients, and 2 of them underwent an endotracheal intubation admission. Diarrhea caused by the vasoactive intestinal peptide was presented in 2 patients with NB. Paroxysmal hypertension was present in 1 patient with 
Table 1 Key characteristics of 77 patients with intraspinal extension

\begin{tabular}{|c|c|}
\hline Characteristic & Number \\
\hline Age (months) & $31 \pm 32$ \\
\hline \multicolumn{2}{|l|}{ Gender } \\
\hline Female & 37 \\
\hline Male & 40 \\
\hline \multicolumn{2}{|l|}{ Symptoms } \\
\hline Asymptomatic & 26 \\
\hline Polypnea & 11 \\
\hline Pain & 11 \\
\hline Paraparesis & 14 \\
\hline Lower extremity weakness & 34 \\
\hline Bladder dysfunction & 16 \\
\hline Constipation & 10 \\
\hline Diarrhea & 2 \\
\hline Hypertension & 1 \\
\hline Lymphadenectasis & 4 \\
\hline Scoliosis & 1 \\
\hline \multicolumn{2}{|l|}{ Location } \\
\hline Cervicothoracic & 22 \\
\hline Thoracic & 45 \\
\hline Thoracolumbar & 10 \\
\hline \multicolumn{2}{|l|}{ Pathology } \\
\hline \multicolumn{2}{|l|}{ Neurogenic } \\
\hline Neuroblastoma & 38 \\
\hline Ganglioneuroblastoma & 13 \\
\hline Ganglioneuroma & 10 \\
\hline Pheochromocytoma & 1 \\
\hline PNET & 2 \\
\hline \multicolumn{2}{|l|}{ Non neurogenic } \\
\hline Lymphoma & 5 \\
\hline Teratoma & 4 \\
\hline Rhabdomyosarcoma & 2 \\
\hline Lipoblastoma & 1 \\
\hline Tuberculosis & 1 \\
\hline \multicolumn{2}{|l|}{ Involvement } \\
\hline Soft tissue & 6 \\
\hline Vertebral body & 23 \\
\hline
\end{tabular}

PNET, primitive neuroectodermal tumor.
Table 2 Neurological outcome in the 48 patients with neurological manifestations

\begin{tabular}{|c|c|c|c|c|c|c|c|c|c|}
\hline \multirow{3}{*}{ Feature } & \multicolumn{9}{|c|}{ Neurological deficits } \\
\hline & \multicolumn{3}{|c|}{ Mild } & \multicolumn{3}{|c|}{ Moderate } & \multicolumn{3}{|c|}{ Severe } \\
\hline & $\mathrm{CR}$ & PR & $S$ & $\mathrm{CR}$ & PR & $S$ & $\mathrm{CR}$ & PR & $S$ \\
\hline \multicolumn{10}{|l|}{ Treatment } \\
\hline Surgery & 7 & 0 & 0 & 6 & 6 & 3 & 3 & 4 & 5 \\
\hline Chemotherapy & 4 & 3 & 4 & 0 & 0 & 1 & 0 & 0 & 2 \\
\hline \multicolumn{10}{|l|}{ Duration (week) } \\
\hline$<1$ & 2 & 0 & 0 & 0 & 0 & 0 & 0 & 0 & 0 \\
\hline $1-4$ & 5 & 1 & 2 & 4 & 0 & 1 & 1 & 2 & 2 \\
\hline$>4$ & 4 & 2 & 2 & 2 & 6 & 3 & 2 & 2 & 5 \\
\hline \multicolumn{10}{|c|}{ CR, complete recovery; PR, partial recovery; S, stationary. } \\
\hline \multicolumn{10}{|c|}{ pheochromocytoma (Table 1). } \\
\hline
\end{tabular}

Neurological manifestations were clinically evident in 48 patients at the time of diagnosis. Of these patients, 14 patients received chemotherapy for initial management of neurological symptoms, while 34 patients underwent neurosurgical decompression. The present study suggested that neurological recovery was correlated with the type of initial treatment modalities and the duration of neurological symptoms at the time of diagnosis. Neurological deficits improved in $76.5 \%$ of patients who underwent neurosurgical intervention and in $50 \%$ of the other patients $(\mathrm{P}=0.094)$. In the mild deficit group, complete recovery occurred in 7 patients $(100.0 \%)$ treated with laminectomy and in 4 patients $(36.4 \%)$ treated with chemotherapy $(\mathrm{P}=0.013)$. None of these patients who received chemotherapy as the first-line treatment showed neurological recovery in the moderate-to-severe groups. Compression manifestations of $\leq 4$ weeks duration showed an improved outcome compared to a longer compression time, with a complete recovery of neurological function in $60 \%$ versus $28.6 \%$ for patients with a longer symptom duration $(\mathrm{P}=0.04)$ (Table 2$)$.

\section{Outcome of $N B$}

Eleven mediastinal NB patients with intraspinal extension received chemotherapy as the primary treatment. Surgery was performed to resect a residual or growing mass after chemotherapy for all 11 patients, and 3 patients (27.3\%) 
underwent a second surgical procedure for the residual mass. Secondary surgery was performed in 5 patients $(100.0 \%)$ with neurosurgery alone and in 4 patients (20\%) with VATS. No patient underwent secondary surgery with a combined thoracic-neurosurgical approach (Table 3).

An initial surgical excision was performed by a combined thoracic-neurosurgical approach in 10 patients. An overall survival rate of $90.0 \% \pm 9.5 \%$ was achieved for patients in the combined thoracic-neurosurgical group, $59.5 \% \pm 15.0 \%$ in thoracotomy group, $40.0 \% \pm 29.7 \%$ in laminotomy group, and $37.0 \% \pm 20.2 \%$ in the chemotherapy group (Figure 2). Complete regression of the tumor was demonstrated in 8 out of 10 patients who underwent a combined thoracicneurosurgical approach as the primary treatment, which was greater than that of patients in other groups $(\mathrm{P}=0.001)$ (Table 3).

\section{Discussion}

Posterior mediastinal tumors can invade the spinal canal, leading to spinal cord compression. This is the largest study focused on posterior mediastinal tumors with intraspinal involvement to the best of our knowledge. One aim of the study was to present the clinical features of these patients. According to previous studies, posterior mediastinal tumors' symptoms were nonspecific and varied depending on the local compression of adjacent tissue $(4,5,16,20)$. Most of these tumors grow asymptomatically until the tumor impacts the adjacent tissue $(20,21)$. In our series, 26 patients $(33.8 \%)$ were completely asymptomatic. Compression of the airway was observed by CT scans in 19 patients including 11 patients with polypnea. MRI documented spinal cord compression in 56 patients, and 44 of them had complaints of neurological symptoms.

The second aim of this study was to investigate the appropriate therapeutic approach for NB with intraspinal involvement. Our present study indicated that surgical approaches might be more appropriate for posterior mediastinal tumors with intraspinal involvement. Firstly, an accurate diagnosis is essential for selecting the optimal chemotherapeutic regimen. In our series, 3 patients with ganglioneuroblastoma were misdiagnosed with ganglioneuroma by FNAC, and we also found 2 patients who had posterior mediastinal NB and intraspinal ganglioneuroma with different histological entities. Consistent with previous studies $(19,20)$, our current data suggests that surgery is recommended to ensure an accurate diagnosis. Secondly, complete resection of neurogenic dumbbell tumors is associated with excellent results $(5,22-24)$. In our study, complete regression of neurogenic dumbbell tumors was observed in 8 out of 10 patients who underwent combined thoracic-neurosurgical approach as the primary treatment. Moreover, the overall survival rate of patients who underwent a combined thoracic-neurosurgical approach was better than that of other patients, although future studies with larger sample sizes are essential to verify these results. Also, consistent with previous studies $(2,11)$, our data confirmed that recovery of neurological function was associated with the initial treatment modality and the duration of the neurological symptoms. Compared to patients who underwent chemotherapy, patients who underwent surgical resection had better neurological function recovery. Patient who received initial chemotherapy were more likely to have progressive neurological deterioration. Based on these findings, we propose that surgery is recommended to collect adequate lesion for histology and molecular analysis. For spinal cord compression in mediastinal $\mathrm{NB}$, a combined thoracic-neurosurgical approach should be considered if complete tumor resection appears feasible for the primary mass in mediastinum.

There are some limitations in our present study. Firstly, laminectomy was reported to be the major risk factor for the development of spinal deformity in the treatment of NB with intraspinal involvement $(6,25,26)$. Spinal deformities tend to be aggravated during puberty $(27,28)$. Over a relatively short follow-up period in our present study, scoliosis or kyphosis were found in 1 patient before any treatment and in 3 patients during chemotherapy. The short-term follow-up might not have been not long enough to detect spinal deformities. These patients are continuously followed up to evaluate whether spinal deformities occur as the patients grow. Secondly, the small sample size and no adjustment for confounders cannot indicate the superiority of one treatment modality over the other. Thirdly, as this study is a retrospective study in our single-center, our findings should be interpreted with cautiously. A prospective study with long-term follow-up is warranted to determine the optimal treatment strategy.

\section{Conclusions}

An accurate and timely diagnosis of posterior mediastinal tumors with intraspinal involvement is challenging, and accurate diagnosis is sufficient to warrant surgical procedures. Our study suggests that a combined thoracic and neurosurgical approach is a safe and effective procedure for mediastinal NB treatment with intraspinal extension. 
Table 3 Characteristics of neuroblastoma with different initial treatment modality

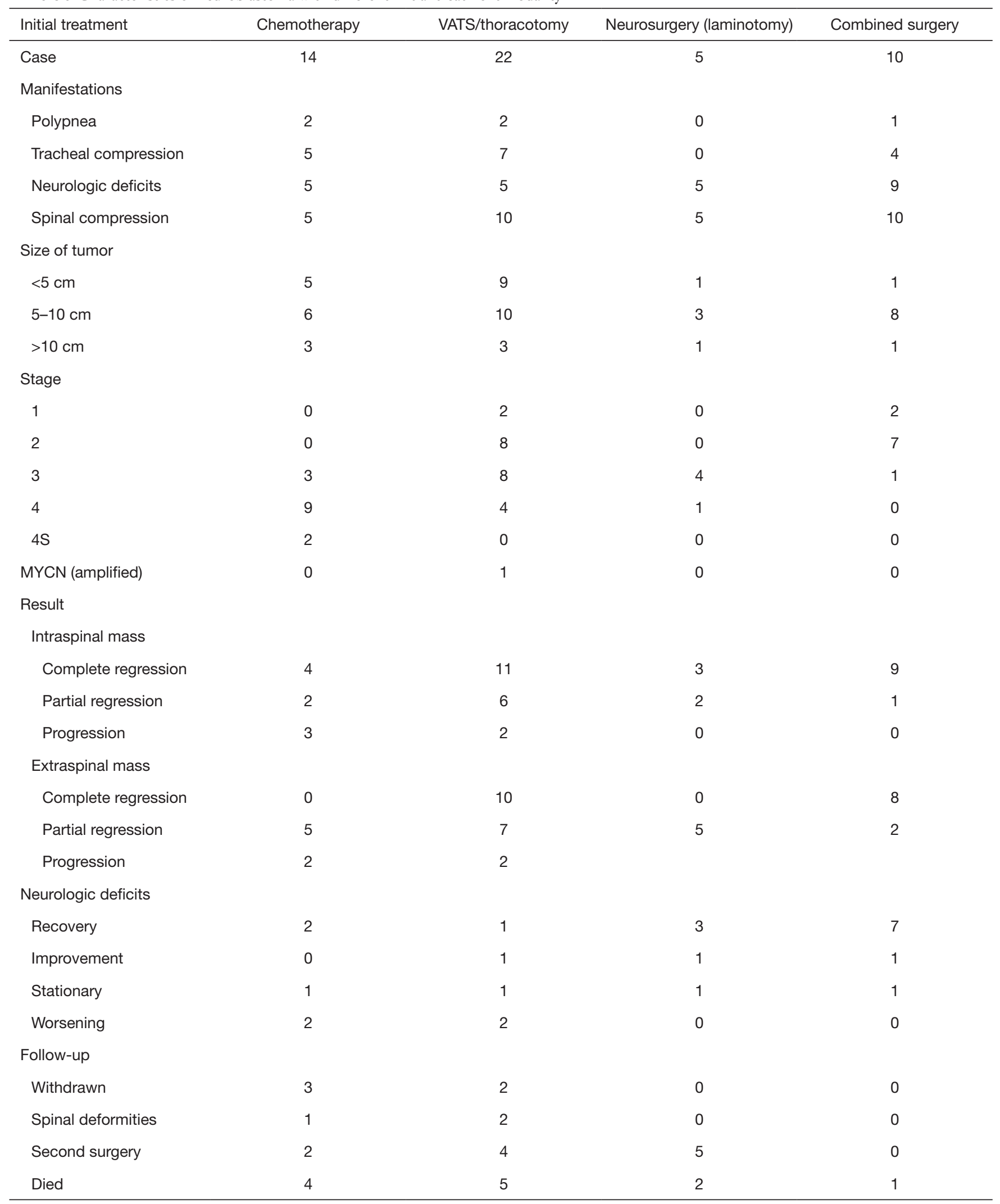

VATS, video-assisted thoracoscopic surgery. 


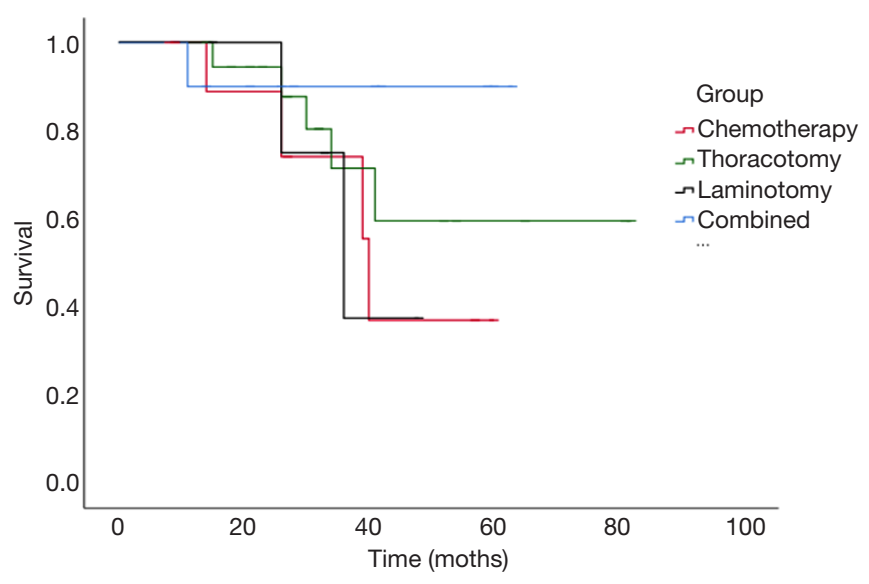

Figure 2 Survival of neuroblastomas with the initial therapeutic modality $(\mathrm{P}=0.405)$.

Further well-designed, prospective studies are encouraged to determine the optimal therapeutic strategy.

\section{Acknowledgments}

Funding: This study was supported by grants from the Science and Technology Projects of Guangzhou Health Committee (No. 20191A011030).

\section{Footnote}

Reporting Checklist: The authors have completed the STROBE reporting checklist. Available at http://dx.doi. org/10.21037/tp-20-268

Data Sharing Statement: Available at http://dx.doi. org/10.21037/tp-20-268

Conflicts of Interest: All authors have completed the ICMJE uniform disclosure form (available at http://dx.doi. org/10.21037/tp-20-268). The authors have no conflicts of interest to declare.

Ethical Statement: The authors are accountable for all aspects of the work in ensuring that questions related to the accuracy or integrity of any part of the work are appropriately investigated and resolved. The study was conducted in accordance with the Declaration of Helsinki (as revised in 2013). This study was approved by the Ethics Committee of Guangzhou Women and children's Medical center (No. 2017120103-2). Written informed consent was obtained from the parents or guardians of each participant.

Open Access Statement: This is an Open Access article distributed in accordance with the Creative Commons Attribution-NonCommercial-NoDerivs 4.0 International License (CC BY-NC-ND 4.0), which permits the noncommercial replication and distribution of the article with the strict proviso that no changes or edits are made and the original work is properly cited (including links to both the formal publication through the relevant DOI and the license). See: https://creativecommons.org/licenses/by-nc-nd/4.0/.

\section{References}

1. De Bernardi B, Balwierz W, Bejent J, et al. Epidural compression in neuroblastoma: Diagnostic and therapeutic aspects. Cancer Lett 2005;228:283-99.

2. Hoover M, Bowman LC, Crawford SE, et al. Long-term outcome of patients with intraspinal neuroblastoma. Med Pediatr Oncol 1999;32:353-9.

3. Kraal K, Blom T, van Noesel M, et al. Treatment and outcome of neuroblastoma with intraspinal extension: A systematic review. Pediatr Blood Cancer 2017;64(8). doi:10.1002/pbc.26451.

4. Abdel Rahman AR, Sedera MA, Mourad IA, et al. Posterior mediastinal tumors: outcome of surgery. J Egypt Natl Canc Inst 2005;17:1-8.

5. Shadmehr MB, Gaissert HA, Wain JC, et al. The surgical approach to "dumbbell tumors" of the mediastinum. Ann Thorac Surg 2003;76:1650-4.

6. Angelini P, Plantaz D, De Bernardi B, et al. Late sequelae of symptomatic epidural compression in children with localized neuroblastoma. Pediatr Blood Cancer 2011;57:473-80.

7. Simon T, Niemann CA, Hero B, et al. Short- and longterm outcome of patients with symptoms of spinal cord compression by neuroblastoma. Dev Med Child Neurol 2012;54:347-52.

8. Nagasako H, Ijichi O, Shinkoda $Y$, et al. Fetal ultrasonography to prevent irreversible neurological sequelae of neonatal neuroblastoma. Pediatr Hematol Oncol 2004;21:157-60.

9. De Martino L, Spennato P, Vetrella S, et al. Symptomatic malignant spinal cord compression in children: a singlecenter experience. Ital J Pediatr 2019;45:80.

10. Kasahara K, Nakagawa T, Kubota T. Neuronal loss and expression of neurotrophic factors in a model of rat chronic compressive spinal cord injury. Spine (Phila $\mathrm{Pa}$ 
1976) 2006;31:2059-66.

11. Fawzy M, El-Beltagy M, Shafei ME, et al. Intraspinal neuroblastoma: Treatment options and neurological outcome of spinal cord compression. Oncol Lett 2015;9:907-11.

12. Katzenstein HM, Kent PM, London WB, et al. Treatment and outcome of 83 children with intraspinal neuroblastoma: the Pediatric Oncology Group experience. J Clin Oncol 2001;19:1047-55.

13. Pi J, Kang Y, Smith M, et al. A review in the treatment of oncologic emergencies. J Oncol Pharm Pract 2016;22:625-38.

14. Hayes FA, Thompson EI, Hvizdala E, et al. Chemotherapy as an alternative to laminectomy and radiation in the management of epidural tumor. J Pediatr 1984;104:221-4.

15. Pollono D, Tomarchia S, Drut R, et al. Spinal cord compression: a review of 70 pediatric patients. Pediatr Hematol Oncol 2003;20:457-66.

16. Yiin JJ, Chang CS, Jan YJ, et al. Treatment of neuroblastoma with intraspinal extensions. J Clin Neurosci 2003;10:579-83.

17. Plantaz D, Rubie H, Michon J, et al. The treatment of neuroblastoma with intraspinal extension with chemotherapy followed by surgical removal of residual disease. A prospective study of 42 patients--results of the NBL 90 Study of the French Society of Pediatric Oncology. Cancer 1996;78:311-9.

18. Loblaw DA, Perry J, Chambers A, et al. Systematic review of the diagnosis and management of malignant extradural spinal cord compression: the Cancer Care Ontario Practice Guidelines Initiative's Neuro-Oncology Disease
Site Group. J Clin Oncol 2005;23:2028-37.

19. Simon T, Hero B, Schulte JH, et al. 2017 GPOH Guidelines for Diagnosis and Treatment of Patients with Neuroblastic Tumors. Klin Padiatr 2017;229:147-67.

20. Newman EA, Abdessalam S, Aldrink JH, et al. Update on neuroblastoma. J Pediatr Surg 2019;54:383-9.

21. Tolbert VP, Matthay KK. Neuroblastoma: clinical and biological approach to risk stratification and treatment. Cell Tissue Res 2018;372:195-209.

22. Ando K, Imagama S, Ito Z, et al. Removal of thoracic dumbbell tumors through a single-stage posterior approach: its usefulness and limitations. J Orthop Sci 2013;18:380-7.

23. Liu HP, Yim AP, Wan J, et al. Thoracoscopic removal of intrathoracic neurogenic tumors: a combined Chinese experience. Ann Surg 2000;232:187-90.

24. Chen X, Ma Q, Wang S, et al. Surgical treatment of posterior mediastinal neurogenic tumors. J Surg Oncol 2019;119:807-13.

25. Sandberg DI, Bilsky MH, Kushner BH, et al. Treatment of spinal involvement in neuroblastoma patients. Pediatr Neurosurg 2003;39:291-8.

26. Paulino AC, Fowler BZ. Risk factors for scoliosis in children with neuroblastoma. Int J Radiat Oncol Biol Phys 2005;61:865-9.

27. Little DG, Song KM, Katz D, et al. Relationship of peak height velocity to other maturity indicators in idiopathic scoliosis in girls. J Bone Joint Surg Am 2000;82:685-93.

28. Charles YP, Daures JP, de Rosa V, et al. Progression risk of idiopathic juvenile scoliosis during pubertal growth. Spine (Phila Pa 1976) 2006;31:1933-42.
Cite this article as: Tang J, Zhang $\mathrm{D}, \mathrm{Xu} \mathrm{YY}$, Xu XK, Wang FH, Zeng JH, Liang JH, Liu W, Li L. Clinical characteristics and therapeutic outcomes of mediastinal neuroblastoma with intraspinal extension: a retrospective study. Transl Pediatr 2021;10(4):715-722. doi: 10.21037/tp-20-268 